\title{
Different modalities of soft tissue coverage of hand and wrist defects
}

Soft tissue defects of hand and wrist with exposed tendons, joints, nerves and bones represent a challenge to plastic surgeons. Such defects necessitate early flap coverage to protect underlying vital structures, preserve hand functions and to allow for early rehabilitation. Many flaps have been described and used for coverage of various soft tissue defects. Of these flaps, there are reversed flow flaps like reversed radial forearm flap, and reversed perforator forearm flaps. The distant flaps used in the reconstruction of hand and fingers are the groin flap, the abdominal flap, the abdominal pocketing procedure and free vascularised flaps. In our study, we used some standard flaps to cover the defects according to the flap availability and feasibilty.

Keywords: hand trauma, exposed structures, flap coverage

\section{Introduction}

Soft tissue defects of hand and wrist with exposed tendons, joints, nerves and bones represent a challenge to plastic surgeons. Such defects necessitate early flap coverage to protect underlying vital structures, preserve hand functions and to allow for early rehabilitation [1].

Direct closure and local flaps represent the most basic techniques on the reconstructive ladder; however, they are inadequate for large or complex defects. Split thickness skin grafts are appropriate for granulating wounds with a bed of vascularized tissue; however, if there is an exposed joint or bone devoid of periosteum or tendon devoid of paratenon, there will be insufficient neovascularization, and the graft will inevitably fail. That is why durable and stable coverage of soft tissue defects of hands with a cutaneous flap seems to be an ideal solution (FIGURE 1a-1e) [1,2].

Many flaps have been described and used for coverage of various soft tissue defects. Of these flaps, there are reversed flow flaps that sacrifice a great vessel like reversed radial forearm flap, and reversed perforator forearm flaps that do not sacrifice vessels [3].

Also there are distant flaps that are often used for the reconstruction of larger defects and offer a great amount of skin without other donor site morbidity to the injured hand. Distant flaps may be pedicle or free flaps (FIGURE 2a-2e) [4].
The standard flaps used in the reconstruction of hand and fingers are the groin flap, the abdominal flap, the bilobed flap, the abdominal pocketing procedure and free vascularised flaps. The Abdominal flap is a time-tested flap that is used for resurfacing degloving injuries of the palm or dorsum of the hand. It has the advantages of ease of elevation, ease of positioning and vascular reliability, while the groin flap is a pedicled flap which is based on the superficial circumflex iliac artery. It provides thin, compliant skin for the thumb, single finger and double finger defects. This flap has the advantage of primary donor site closure, hidden donor site, vascular reliability and versatile use [5].

Free flap use is a time consuming procedure, requires a well experienced team, specific instruments and a complicated postoperative care [4].

\section{Material and methods}

At the Plastic Surgery Department of Ahmed Maher Teaching hospital, from January 2014 to December 2015 we harvested different flaps for reconstructing different soft tissue defects of the hand caused by different types of trauma. Demographic data causes and sites of defects were analysed.

The flaps harvested varied according to the site of defect. Flaps used were abdominal flaps, groin flaps, and forearm flaps (reversed flow radial forearm flap, adipo-fascial forearm flap, and reversed flow perforator flap) (FIGURE 3a-3d).
Belal Abdullah

Almobarak, Mohamed Elsayed

Mohamed* \&

Mohamed Ibrahim

\section{Hassan}

Ahmed Maher Teaching Hospital, Cairo, Egypt

*Author for correspondence: mghabn5777@yahoo.com 

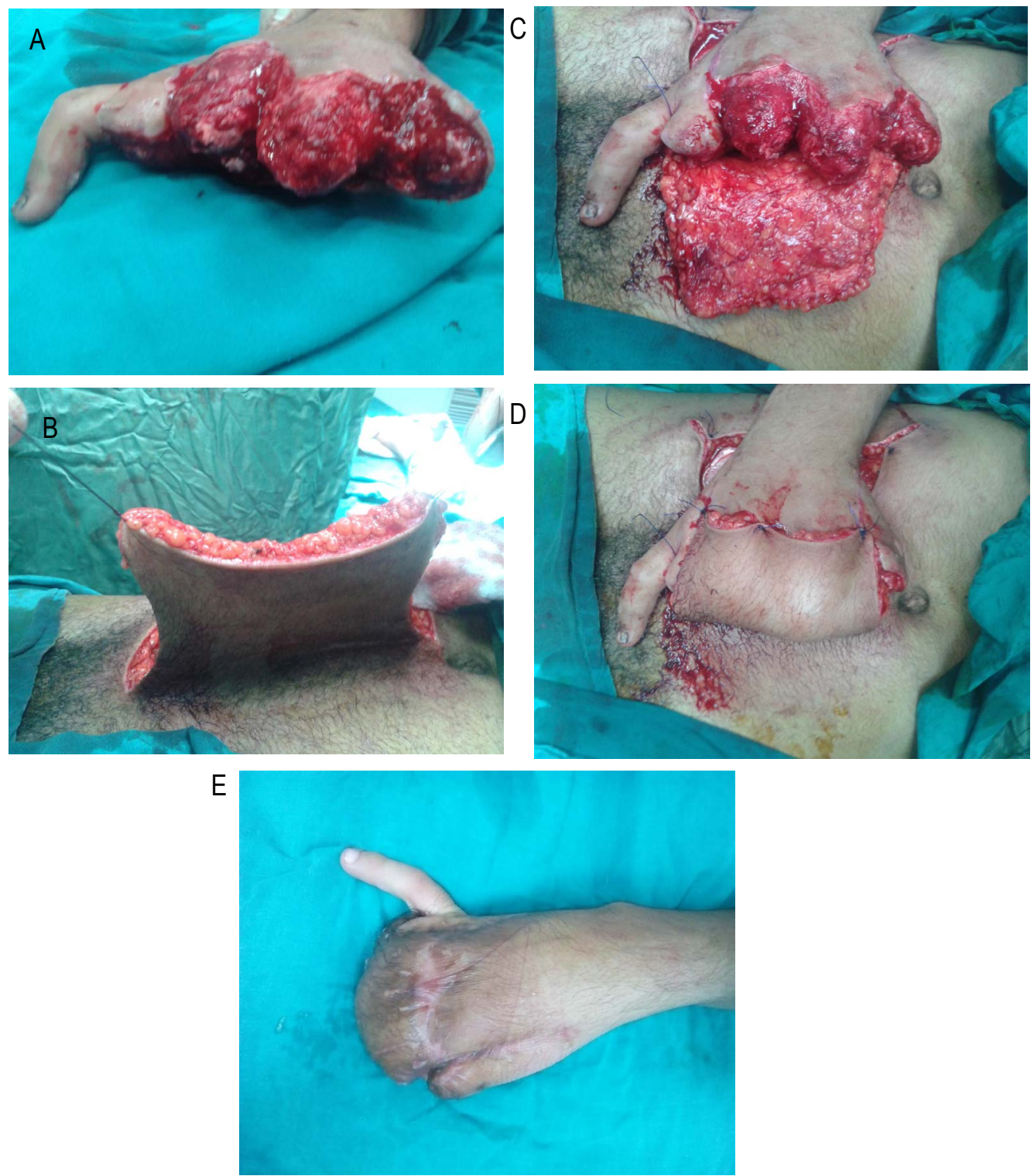

FIGURE 1A-1E.. Case (1): Male patient 18 years old with RTA with amputation of lateral 4 digits and exposed metacarpal and carpal bones. Patient underwent abdominal flap to cover defects over palm and fingers.

a) Pre-operative raw area of the amputated fingers.

b) Elevation of abdominal flap.

c) Application of the flap to the raw area.

d) Fixation of the flap to the hand.

e) Post-operative view (2months).

Some flaps needed a second stage either for division 3 weeks after the time of primary reconstruction (abdominal flaps and groin flaps) or for debulking and separation of fingers if they are involved in reconstruction 3 months after time of reconstruction. The size of the harvested flap, the harvesting time, results of flap transfers, and flap-related complications were analysed. A major complication was defined as necrosis and loss of any part of the flap that needed further interference while epidermolysis, dehiscence, or hematoma leading to impairment of wound healing was defined as a minor complication (FIGURE4a-4f).

\section{Results}

(19) Patients (13) males and (6) females underwent reconstruction of different soft tissue hand defects using (20) different flaps (12 abdominal flaps, 2 groin flaps and 6 forearm 

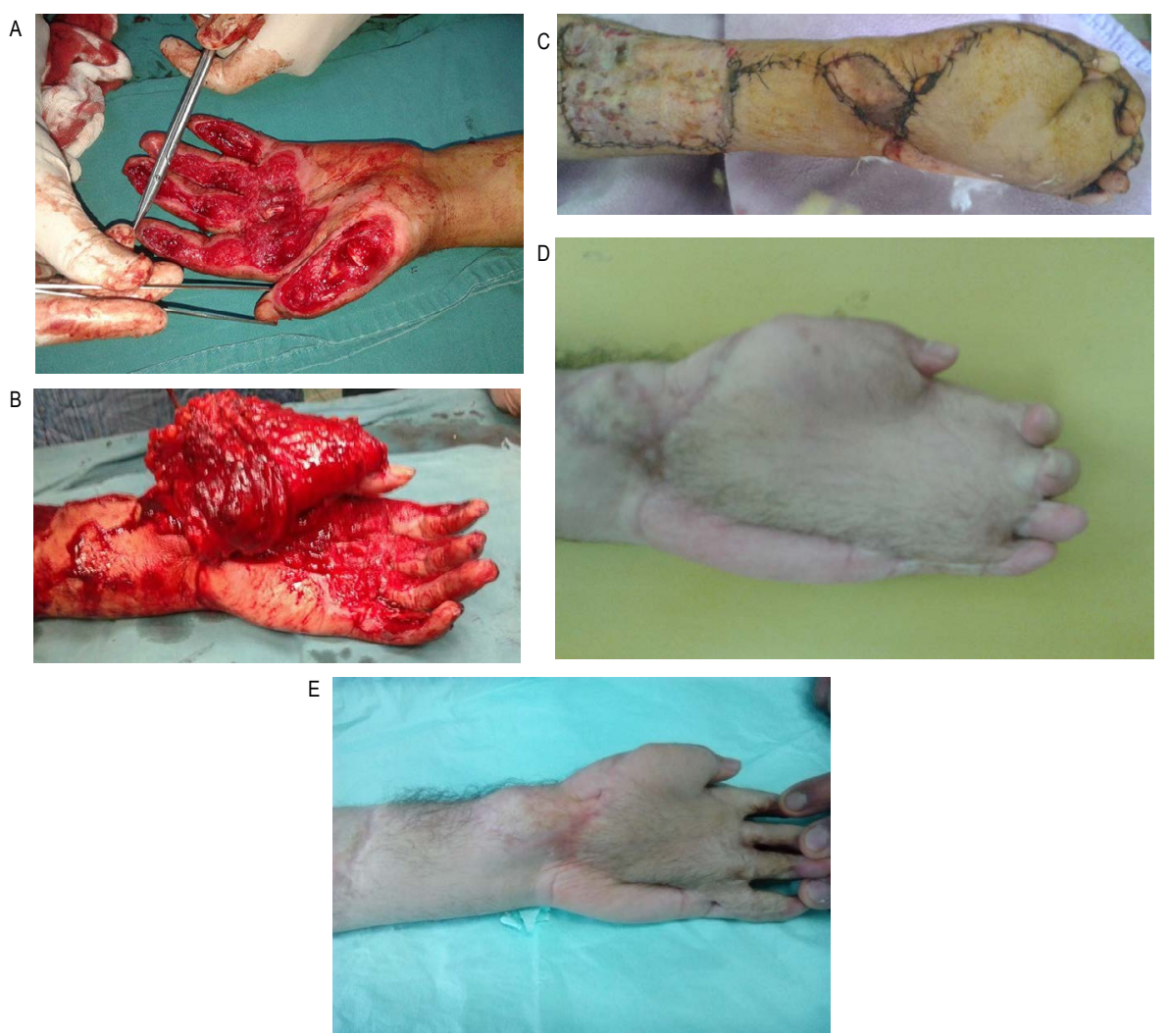

FIGURE 2A-2E. Case (2): Male patient 30 years old with RTA with exposed palmar structures fingers. Patient underwent radial artery perforator flap to cover defects over palm and fingers.
a) Pre-operative raw area of the palm and volar aspect of the fingers.
b) Elevation of reversed radial forearm flap.
c) Early post -operative view.
d) One month post-operative view.
e) Three months Post-operative view after release of syndactyly.
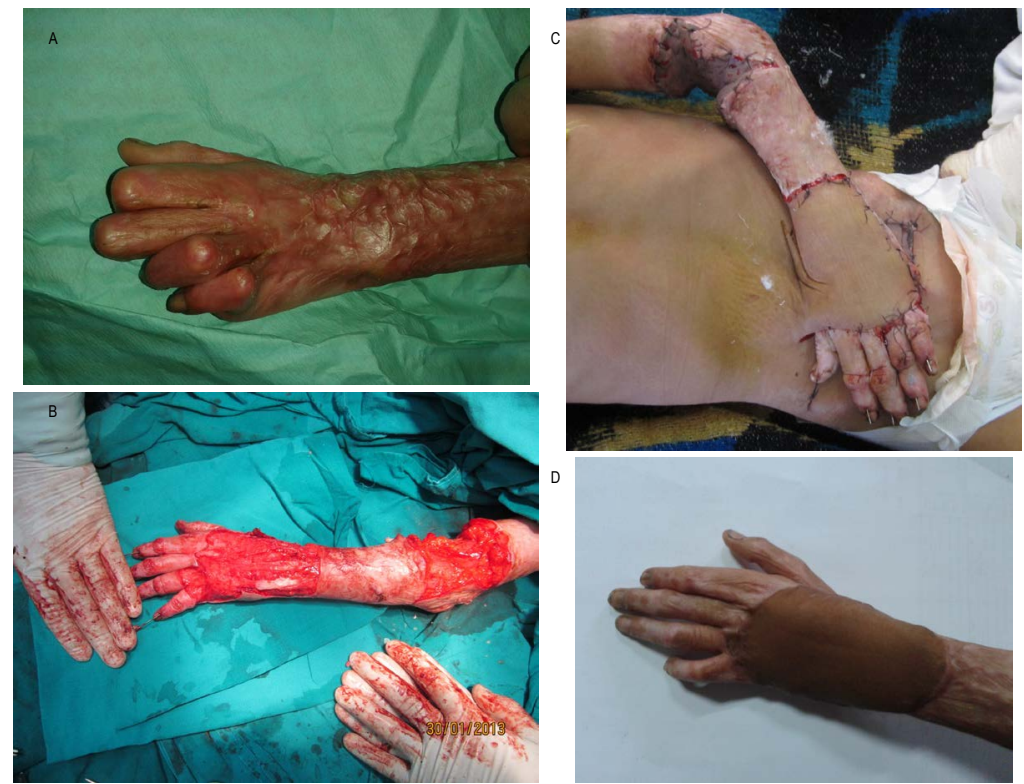

FIGURE 3A-3D. Case (3): Male child 6 years old with post burn contracted fingers and hand, excision of the scared fibrous tissue and abdominal flap, after second stage and separation of the flap.

a) Pre-operative view of post-burn hypertrophic scaring and contracted fingers.

b) Excision of the scar tissue.

c) Fixation of the flap to the hand.

d) Post-operative view (3months). 
A
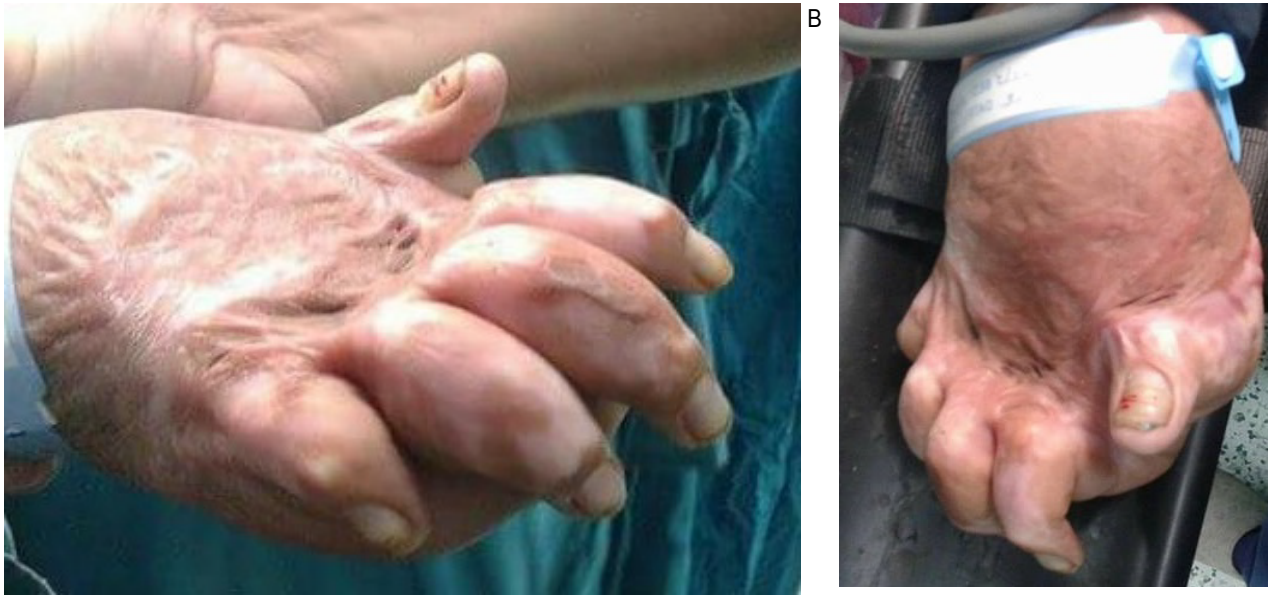

C

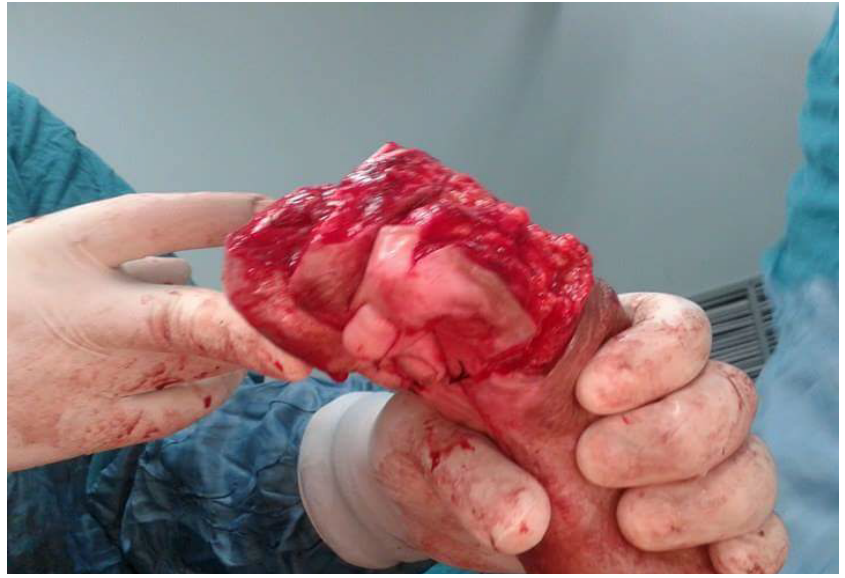

D
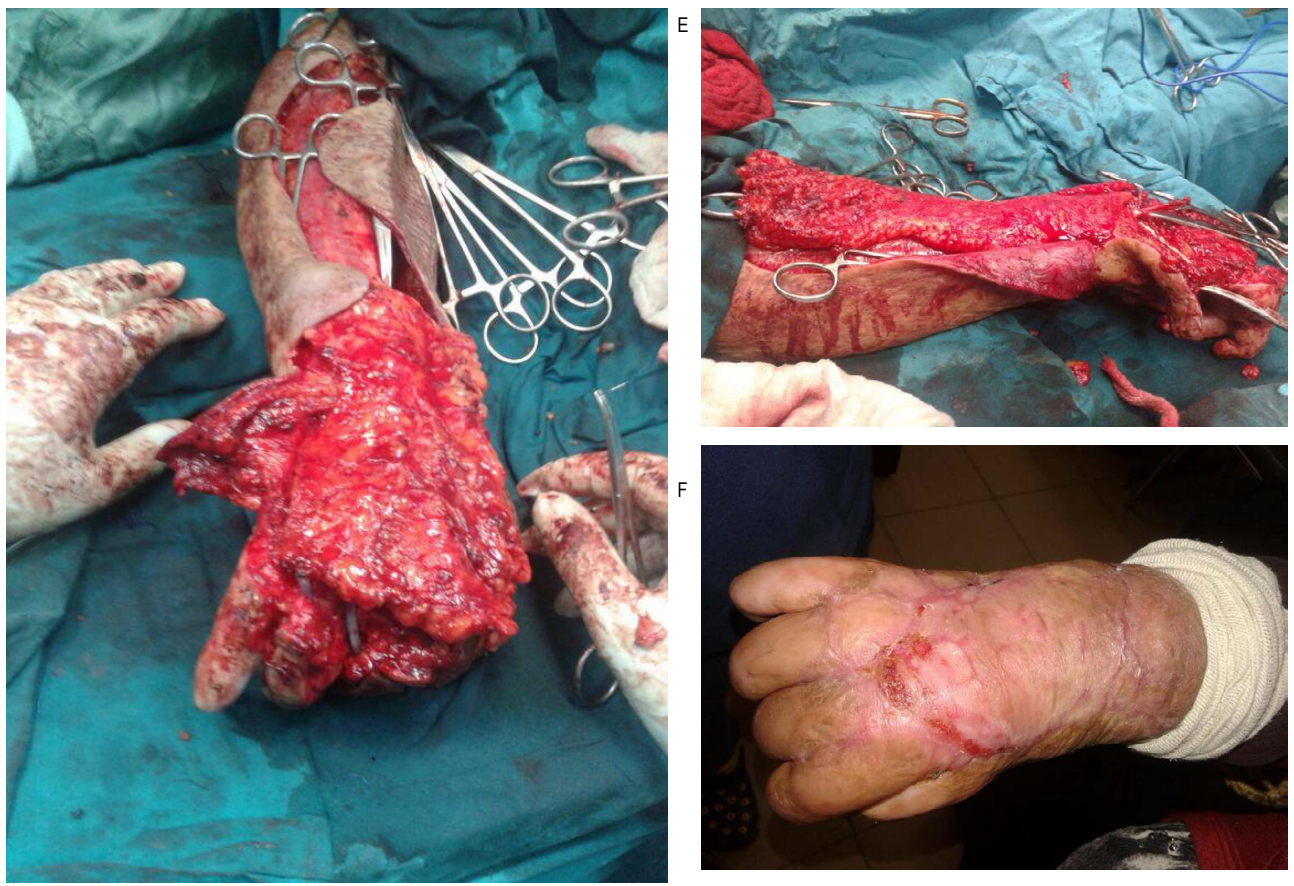

FIGURE 4A-4F. Case (4): Female patient 29 years old with post burn mutilated hand, excision of the scared fibrous tissue and and turn-over adipo-fascial forearm flap and STSG fixed over the flap.

a. Pre-operative raw area of the contracted hand and fingers.

b. Excision of the scar tissue and contractures.

c. Application of the reversed radial artery perforator flap to the raw area.

d. Fixation of the flap to the hand.

e. Post-operative view (1 month). 


\begin{tabular}{|c|c|c|c|c|}
\hline & Sex & Parts affected & Flaps used & Complications \\
\hline 1 & M & Palm and fingers & Reversed radial forearm flap & Non \\
\hline 2 & M & Dorsum & Abdominal flap & Non \\
\hline 3 & M & Ulnar side, palm and wrist & Radial forearm flap & $\begin{array}{l}\text { Epidermolysis, Treated } \\
\text { conservatively }\end{array}$ \\
\hline 4 & $\mathrm{~F}$ & Mutilated hands(bilateral) & $\begin{array}{l}\text { Abdominal flaps (turn-over } \\
\text { adipo-fascial forearm flap+ } \\
\text { STSG) }\end{array}$ & Non \\
\hline 5 & $\mathrm{~F}$ & Amputation(mid-palmar) & Groin flap & Infection treated conservatively \\
\hline 6 & $M$ & Dorsum & Radial perforator flap & Non \\
\hline 7 & M & Fingers(flexor aspect) & Abdominal flap & Non \\
\hline 8 & $\mathrm{~F}$ & Dorsum & Abdominal flap & Non \\
\hline 9 & M & Fingers & Groin flap & Non \\
\hline 10 & M & Radial aspect of hand & Radial Perforator flap & Epidermolysis, needed grafting \\
\hline 11 & M & Wrist and forearm & Abdominal flap & Non \\
\hline 12 & M & Palm & Abdominal flap & Non \\
\hline 13 & $\mathrm{~F}$ & Dorsum & Abdominal flap & $\begin{array}{l}\text { Epidermolysis, Treated } \\
\text { conservatively }\end{array}$ \\
\hline 14 & M & Mid-palm amputation & Abdominal flap & $\begin{array}{l}\text { Slight dehiscence, Treated } \\
\text { conservatively }\end{array}$ \\
\hline 15 & M & Dorsum & Abdominal flap & Non \\
\hline 16 & $\mathrm{~F}$ & Mutilated hand (Lt) & Abdominal flap & Dehiscence, needed grafting \\
\hline 17 & M & Wrist & Radial perforator flap & Non \\
\hline 18 & $\mathrm{~F}$ & Dorsum & Radial perforator flap & Non \\
\hline 19 & M & Dorsum & Abdominal flap & Non \\
\hline
\end{tabular}

Table 2. Total number of flaps for hand and wrist resurfacing.

\begin{tabular}{|c|c|}
\hline Flap & Total number \\
\hline Abdominal flap & 12 \\
\hline $\begin{array}{c}\text { turn-over adipo-fascial forearm } \\
\text { flap+ STSG }\end{array}$ & 1 \\
\hline Groin flap & 2 \\
\hline Radial perforator flap & 4 \\
\hline Reversed radial forearm flap & 1 \\
\hline Total number & 20 \\
\hline
\end{tabular}

flaps). The hand defects involved the palm, dorsum of hand, wrist, and fingers, caused by sharp or blunt trauma, burn, or degloving injuries.

Patients' data and Operative procedures for hand and wrist resurfacing are shown in TABLE 1.

The average times of flap harvest were between 30 minutes to 90 minutes according to the type of the flap (the shortest time was that for the abdominal flap while the longest was that for reversed radial forearm flap and reversed forearm perforator flap).

The overall Complications occurred in 6 flaps, 4 minor complications which were treated conservatively and 2 major which needed grafting. The remaining flaps showed no complications and passed an uneventful follow up period representing $70 \%$ of flaps.

Mean follow-up periods were about 3 to 12 months in all types of flaps.

TABLE 2 shows the total number of flaps for hand and wrist resurfacing.

\section{Discussion}

Soft tissue defects of hands require early coverage so that physiotherapy can be commenced as early as possible. Coverage is necessary to replace missing skin and to protect exposed structures [1].

Local flaps represent the first step on the reconstructive ladder; however, they are inadequate for large or complex defects [2].

Several forearm flaps are used to cover the hand and wrist. These include the reverse pedicle radial forearm flap, radial forearm fascial flap, radial forearm perforator flap, ulnar artery flap and the posterior interosseous artery flap [6].

When the defect cannot be closed primarily, cannot support STSG or FTSG, and local tissue is not available or sufficient, distant axial pattern flaps are the option of choice [7].

A well designed pedicled flap is a good 
foundation to make any secondary procedures possible. They also score relatively well when compared to other free skin flaps like ALT, which also would be very bulky when used for circumferential defects. In addition, free flaps cannot be thinned as well as the pedicled flaps as it is more difficult to thin a free flap soon after the operation [8].

During our study, we used 6 forearm flaps of different types for coverage of the dorsum, palm and the proximal parts of the fingers. Also, we used 12 abdominal flaps to reconstruct dorsum, palm and whole fingers whenever there is lack of forearm flaps or the defects are too large to be covered with forearm flaps. Minor complications occurred in only 4 representing $20 \%$ of flaps while major complications occurred in only 2 cases representing $10 \%$ of flaps. All flaps showed no loss or necrosis and the coverage of all defects was satisfactory.

With the use of forearm flaps we could cover defects up to $8 \mathrm{~cm} \times 8 \mathrm{~cm}$, while with the use of abdominal flaps we could cover large defects up to $10 \mathrm{~cm} \times 15 \mathrm{~cm}$. This agrees with Brian and Kevin who stated that the ideal use for distant flaps is in the setting of a large defect, with the zone of injury eliminating local and regional reconstructive options [9].

Our results go in the same way with the studies of (Burstein et al. and Fisher and Davis et al.) who reported that distant axial fasciocutaneous flaps are a reliable option in hand and upper extremity reconstruction [1012].

Also, we believe that two-stage flaps are a useful alternative when microsurgical techniques are unavailable and the main limitation for their use is the need for prolonged immobilization and donor site morbidity.

\section{Conclusion}

Soft tissue defects of the hand can be reconstructed effectively with the use of either forearm flaps or other pedicled flaps like abdominal and groin flaps with a minor or no complications. These flaps are easy to harvest and can be done with neither specific instruments nor advanced training needed for free flap reconstruction. 


\section{REFERENCES}

Khan MM, Yaseen M, Bariar LM, Khan SM. Clinical study of dorsal ulnar artery flap in hand reconstruction. Indian J. Plast. Surg. 42(1), 52-57 (2009).

Kaufman MR, Jones NF. The reverse radial forearm flap for soft tissue reconstruction of the wrist and hand. Tech. Hand Up Extrem. Surg. 9(1), 4751 (2005).

Bocchi A, Quarta L, Castri AD, Boschi E, Caleffi E. Reverse Perforator Flaps in the Reconstruction of the Hand. Our Clinical Experience. Open Orthopaed. J. 11(4) (2017).

Takahashi M, Kasai T, Nishisho T, et al. Reverse Adipofascial Flap after Resection of a Malignant Perineurioma of the Forearm. Orthoped. 37(7), e661-e664 (2014).

Krishnamoorthy R, Karthikeyan G. Degloving injuries of the hand. Indian J. Plast. Surg. 44(2), 227-236 (2011).

Matsui J, Piper S, Boyer MI. Nonmicrosurgical options for soft tissue reconstruction of the hand. Curr. Rev. Musculoskelet. Med. 7(1), 68-75 (2014).

Goertz O, Kapalschinski N, Daigeler A, et al. The effectiveness of pedicled groin flaps in the treatment of hand defects: results of 49 patients. J. Hand Surg. 37, 2088-2094 (2012).

Sabapathya SR, Venkatramania $\mathrm{H}$, Playab PM. The use of pedicled abdominal flaps for coverage of acute bilateral circumferential degloving injuries of the hand. Trauma Case
Reports (1)3-4, 25-31 (2015).

Brian PK, Chung KC. MS2 soft tissue coverage for elbow trauma. Hand Clin. 31(4), 693-703 (2015).

Burstein FD, Salomon JC, Stahl RS. Elbow joint salvage with the transverse rectus island flap: a new application. Plast. Reconstruct. Surg. 84(3), 492-497 (1989).

Fisher J. External oblique fasciocutaneous flap for elbow coverage. Plast. Reconstruct. Surg. 75(1), 51-61 (1985).

Davis WM, McCraw JB, Carraway $\mathrm{JH}$. Use of a direct, transverse, thoracoabdominal flap to close difficult wounds of the thorax and upper extremity.

Plast. Reconstruct. Surg. 60(4), 526-533 (1977). 